\title{
COMPARAÇÃO DA COMPOSIÇÃO QUÍMICA E DA ATIVIDADE ANTIOXIDANTE DE \\ FOLHAS E CAULE DE Lippia alnifolia Mart. \& Schauer.
}

\author{
Horácio Freitas Bomfim $^{1}$; Angélica Maria Lucchese ${ }^{2}$; Maira Meira de Freitas ${ }^{3}$ e \\ Iza M. M. Paulo ${ }^{4}$ \\ 1. Bolsista PIBIC/FAPESB, Graduando em Farmácia, Universidade Estadual de Feira de Santana, e-mail: \\ hfreitasb@gmail.com \\ 2. Orientadora, Departamento de Exatas, Universidade Estadual de Feira de Santana, e-mail: \\ angelica.lucchese@gmail.com \\ 3. Participante do projeto, Departamento de Saúde, Universidade Estadual de Feira de Santana, e-mail: \\ mairafreitas_s2@hotmail.com \\ 4. Participante do projeto, Doutoranda em Biotecnologia, Universidade Estadual de Feira de Santana, e-mail: \\ izamiranda@live.com
}

PALAVRAS-CHAVE: Antioxidante; Frações; Lippia alnifolia;

\section{INTRODUÇÃO}

Lippia alnifolia Mart. \& Schauer, conhecida também como pedrécio, alecrim de vaqueiro, alecrim do mato, tem uso popular no tratamento de feridas ou queimaduras de pele. Também é empregado na forma de tintura para uso tópico, com a mesma finalidade, ou como gargarejo e bochecho nas infecções de garganta e da boca, ou em lavagens vaginais contra infecções. Essa mesma tintura, usada na forma de compressas locais, é muito eficiente no tratamento de acne, sarna infectada, panos brancos, impingem, caspas e mau cheiro dos pés, axilas e virilhas (Agra et al., 2008).

Em estudos da atividade antioxidante realizado pelo nosso grupo de pesquisa com os extratos metanólicos das folhas e dos caules de Lippia alnifolia, utilizando o método de sequestro de radicais livres DPPH, a espécie demonstrou um excelente potencial antioxidante, com $\mathrm{CE}_{50}$ de 38,65 e $38,00 \mu \mathrm{g} / \mathrm{mL}$, respectivamente (resultados não publicados). Quando comparado com outra espécie do mesmo gênero, como é o exemplo de Lippia graveolens com CE50 entre 152 a $207 \mu \mathrm{g} / \mathrm{mL}$ (Martínez-Rocha, et al., 2008), observa-se o quanto foram expressivos os resultados encontrados, demostrando a importância da continuidade dos estudos com a espécie Lippia alnifolia. Deste modo a realização de novos testes utilizando as frações hidrometanólica e clorofórmica dos extratos das folhas e dos caules, se faz necessário para a seleção da fração mais ativa para posterior identificação e isolamento dos metabolitos ativos.

\section{MATERIAL E MÉTODOS}

O extrato metanólico das folhas e dos caules de Lippia alnifolia foi fracionado por partição líquido-líquido para obtenção das frações, no qual $20 \mathrm{~g}$ do extrato metanólico bruto foi ressuspenso em metanol:água $(7: 3 \mathrm{v} / \mathrm{v})$ e extraído com clorofórmio para obtenção das frações clorofórmica e hidrometanólica, visando uma semipurificação das substâncias através de suas polaridades. As frações clorofórmicas foram concentrada em evaporador rotatório e colocada para secar em capela de exaustão, enquanto as frações hidrometanólicas tiveram o metanol retirado no evaporador rotatório e a solução final foi liofilizada.

O teor de fenólicos foi determinado por espectrometria no UV-Vis $(750 \mathrm{~nm})$, pelo método de Folin-Ciocalteau, utilizando ácido gálico (AG) como padrão (Peres, 2009). A determinação de flavonoides foi por reação com $\mathrm{AlCl}_{3}$ em espectrometria no UV-Vis (425 nm), utilizando quercetina (Q) como padrão (Banov, 2006).

A atividade antioxidante foi determinada através do método de sequestro do radical livre 1,1-difenil-2-picrilhidrazila (DPPH) (Sousa, et al.,2007). As soluções das frações clorofórmica das folhas foram preparadas nas concentrações de $40 \mu \mathrm{g} / \mathrm{mL} ; 80$ 
$\mu \mathrm{g} / \mathrm{mL} ; 120 \mu \mathrm{g} / \mathrm{mL} ; 160 \mu \mathrm{g} / \mathrm{mL} ; 200 \mu \mathrm{g} / \mathrm{mL}, 240 \mu \mathrm{g} / \mathrm{mL}, 280 \mu \mathrm{g} / \mathrm{mL}$; fração hidrometanólica das folhas com concentrações de $5 \mu \mathrm{g} / \mathrm{mL} ; 10 \mu \mathrm{g} / \mathrm{mL} ; 15 \mu \mathrm{g} / \mathrm{mL} ; 20$ $\mu \mathrm{g} / \mathrm{mL}$ e $25 \mu \mathrm{g} / \mathrm{mL}$; fração clorofórmica do caule com concentrações de $150 \mu \mathrm{g} / \mathrm{mL}$, $200 \mu \mathrm{g} / \mathrm{mL}, 250 \mu \mathrm{g} / \mathrm{mL}, 300 \mu \mathrm{g} / \mathrm{mL}, 350 \mu \mathrm{g} / \mathrm{mL}, 350 \mu \mathrm{g} / \mathrm{mL}, 400 \mu \mathrm{g} / \mathrm{mL}$ e $450 \mu \mathrm{g} / \mathrm{mL}$; e fração hidrometanólica dos caules com concentrações de $5 \mu \mathrm{g} / \mathrm{mL} ; 10 \mu \mathrm{g} / \mathrm{mL} ; 15$ $\mu \mathrm{g} / \mathrm{mL} ; 20 \mu \mathrm{g} / \mathrm{mL} ; 25 \mu \mathrm{g} / \mathrm{mL}$ e $30 \mu \mathrm{g} / \mathrm{mL}$. A atividade antioxidante foi expressa pelo $\mathrm{CE}_{50}$ (quantidade necessária para sequestrar $50 \%$ do radical livre). Ácido ascórbico e trolox foram utilizados como controles positivos. Todos os ensaios foram realizados em triplicata.

\section{RESULTADOS E DISCUSSÃO}

As frações clorofórmica e hidrometanólica oriundas da partição do extratos de folhas e caules, após secas, foram devidamente pesadas e os dados de rendimentos estão apresentados na Tabela 1. É possível verificar que as frações hidrometanólicas obtiveram maior rendimento que as clorofórmicas, sugerindo assim a predominância de compostos mais polares nos extratos.

Tabela 1: Rendimento das frações clorofórmica e hidrometanólica provenientes do extrato bruto das folhas e caules de Lippia alnifolia.

\begin{tabular}{l|c}
\hline Frações & Rendimento (\%) \\
\hline Clorofórmica folha & 23,74 \\
\hline Hidrometanólica folha & 68,55 \\
\hline Clorofórmica caule & 20,08 \\
\hline Hidrometanólica caule & 71,12 \\
\hline
\end{tabular}

Os dados do teor de fenólicos e flavonoides totais das frações clorofórmica e hidrometanólica das folhas e dos caules estão reunidos na tabela 2 , onde é apresentada a média da triplicata, bem como o desvio padrão.

Tabela 02. Teor de fenólicos e flavonoides totais das frações cloroformica e hidrometanolica das folhas e caules de Lippia alnifolia.

\begin{tabular}{|c|c|c|}
\hline Frações & $\begin{array}{c}\text { Fenólicos } \\
\text { Média }( \pm D P) ~ m g \\
\text { EAG/g }\end{array}$ & $\begin{array}{c}\text { Flavonoides } \\
\text { Média ( } \pm \text { DP) } \\
\text { mg EQ/g }\end{array}$ \\
\hline Clorofórmica folha & $81,17 \pm 1,53$ & $32,41 \pm 0,80$ \\
\hline Hidrometanólica folha & $374,17 \pm 2,47$ & $27,76 \pm 0,54$ \\
\hline Clorofórmica caule & $72,83 \pm 2,08$ & $7,60 \pm 0,12$ \\
\hline Hidrometanólica caule & $329,5 \pm 23,44$ & $6,11 \pm 0,55$ \\
\hline
\end{tabular}


Os compostos fenólicos, além de proporcionar atividade antioxidante que prolongam o armazenamento de produtos, têm demonstrado importante atividade "in vivo" e podem ser benéficos no controle de diversas doenças relacionadas à formação excessiva de radicais livres que excedem a capacidade de defesa antioxidante do corpo humano como aterosclerose, cataratas e câncer (Ramarathnam et. al., 1995). O teor de compostos fenólicos e flavonoides totais observados na tabela 02 indicam o potencial das folhas e dos caules da Lippia alnifolia como fonte de compostos antioxidantes.

Não houve correlação entre os valores de fenólicos e de flavonoides para as frações analisadas, pois as frações hidrometanólicas apresentaram o maior teor de fenólicos, enquanto as clorofórmicas o maior teor de flavonoides. Esta variação pode ser decorrente da presença de outros compostos fenólicos mais polares que não os flavonoides, e da interferência do método adotado na quantificação de flavonoides. No mesmo, o cloreto de alumínio é um agente complexante, que aumenta o comprimento de onda da absorção máxima, intensificando-a, evitando assim a interferência de outros compostos fenólicos na leitura. Mas os complexos de flavonóis com alumínio absorvem próximos a faixa de $425 \mathrm{~nm}$, enquanto as flavonas, por exemplo, absorvem em comprimentos de onda inferiores, podendo dessa forma ter ocorrido uma subestimação do valor de flavonoides na mistura, em função de diferentes classes destes metabólitos (Mabry, Markham, Thomas, 1970).

Os dados da atividade antioxidante, avaliada pelo sequestro do radical livre $\mathrm{DPPH}$, estão representados pelo $\mathrm{CE}_{50}$ obtido pela média das triplicatas das frações clorofórmica e hidrometanólica do extratos de folhas e caules calculados por regressão linear. A média dos valores de $\mathrm{CE}_{50}$ dos extratos e dos controles positivos (ácido ascórbico e Trolox) estão apresentados na Tabela 3.

Tabela 03. Valores médios de $\mathrm{CE}_{50}$ das frações clorofórmica e hidrometanólica das

folhas e caules de Lippia alnifolia, do ácido ascórbico e Trolox em $\mu \mathrm{g} / \mathrm{mL}$

$$
\text { fração/ Padrão }{ }^{*} \mathbf{C E}_{50}
$$

Fração clorofórmica folha Média $( \pm \mathrm{DP}) \boldsymbol{\mu \mathrm { g } / \mathbf { m L }} \quad 225,51 \pm 8,53$

Fração hidrometanólica folha Média $( \pm \mathrm{DP}) \boldsymbol{\mu \mathrm { g } / \mathbf { m L }} \quad 16,85 \pm 2,00$

Fração clorofórmica caule Média $( \pm \mathrm{DP}) \boldsymbol{\mu g} / \mathbf{m L} \quad 311,49 \pm 10,67$

Fração hidrometanólica caule Média ( $(\mathbf{D P}) \boldsymbol{\mu g} / \mathbf{m L} \quad 22,17 \pm 0,75$

Trolox 12,05

Ácido ascórbico 10,11

Trolox/Acido Ascórbico (Padrões Utilizados) DP (Desvio Padrão)* EC Ev $_{5}$ para atividade antioxidante pelo sequestro de radicais livres.

$\mathrm{Na}$ atividade antioxidante, utilizando o método de DPPH, quanto menor for o $\mathrm{CE}_{50}$ de uma amostra, maior é a sua atividade antioxidante, já que a mesma necessita de concentrações menores para um maior consumo de DPPH. É possível verificar-se (tabela 3) que as frações hidrometanólicas apresentaram menor $\mathrm{CE}_{50}$, com destaque para a fração hidrometanólica das folhas. Os resultados aqui encontrados estão correlacionados com os valores de fenólicos encontrados (tabela 2), indicando assim 
que compostos fenólicos são os principais metabolitos secundários responsáveis pela atividade antioxidante.

\section{CONSIDERAÇÕES FINAIS}

Os teores de fenólicos e flavonoide e a atividade antioxidante pelo método de sequestro de radicais livres DPPH sugerem que as frações apresentam potencial na busca por novas substâncias com atividade antioxidante, com destaque para as frações hidrometanólicas. Assim, estudos visando o isolamento e a identificação dos compostos presentes nas frações estão em andamento.

\section{REFERÊNCIAS}

AGRA, M. F., et al. Survey of medicinal plants used in the region Northeast of Brazil. Rev Bras Farmacogn. 18: 472-508, 2008

BANOV, D. et al. Caracterização do extrato seco de Ginkgo biloba L. em formulação de uso tópico. Acta Form. Bonaerense 25(2) : 219-24.2006.

MABRY, T.J. et. al. The systematic identification of flavonoids. Springer: Berlin, 1970.

MARTÍNEZ-ROCHA, A. et al. Antioxidant and Antimutagenic Activities of Mexican Oregano (Lippia graveolens Kunth). Plant foods for human nutrition. 2008.

PERES, M. T. L. P et al. Estudos químicos e biológicos de Microgramma vacciniifolia (Lansd. \& Fisch.) Copel (Polypodiaceae). Química Nova, v. 32, n.4, p. 897-901. 2009.

SOUSA, C. M. M. et al. Fenóis totais e atividade antioxidante de cinco plantas medicinais. Química Nova, v. 30, n.2. p. 351-355, 2007. 